Article

\title{
Experimental Investigation of the Multi-Physical Properties of an Energy Efficient Translucent Concrete Panel for a Building Envelope
}

\author{
Baofeng Huang ${ }^{1, *(1)}$ and Wensheng $\mathrm{Lu}^{2}$ \\ 1 College of Civil Engineering, Nanjing Tech University, Nanjing 211800, China \\ 2 College of Civil Engineering, Tongji University, Shanghai 200092, China; wally@tongji.edu.cn \\ * Correspondence: baofeng@njtech.edu.cn
}

Received: 12 August 2020; Accepted: 4 September 2020; Published: 29 September 2020

\begin{abstract}
The multi-physical properties of the building envelope play a major role in the energy efficiency of buildings. Translucent concrete panels (TCPs) with various volumetric ratios of optical fibers (OFs) were cast. To understand the multi-physical properties of the TCP for the building envelope, compressive strength, thermal and light transmittance tests were carried out. The compressive strength test showed that TCP with light-weight mortar (LWM) has higher strength compared to that with normal-weight mortar (NWM), but it did not exhibit an apparent ductile behavior. The U-values of the plain panel were 4.25 and $5.45 \mathrm{~W} /\left(\mathrm{m}^{2} \mathrm{~K}\right)$ for TCPs with the LWM and NWM, respectively. The existence of the OFs improved the thermal insulation property. The K-values of the LWM TCP were smaller than that of the common façade, which proved its excellent energy-efficient performance. The solar heat gain coefficients (G-values) of the two tested TCP types-LWM and NWM-were 0.198 and 0.242 , respectively. The visible light transmission test showed that the light transmitted by the TCP was proportional to the density of the OFs in a matrix of concrete. The experimental light acceptance angle of the OF was close to the computational value $\left(35^{\circ} \mathrm{C}\right)$. Therefore, all the experimental results demonstrated that TCPs can improve the energy efficiency of buildings.
\end{abstract}

Keywords: building envelope; translucent concrete; compressive strength; energy efficient; solar heat gain; thermal transmittance; light transmittance

\section{Introduction}

Sustainable development has recently become an unavoidable trend in variable disciplines, including civil engineering and architecture. Therefore, the development and use of sustainable materials, which are energy-efficient and low-cost, has attracted increased interest. The building envelope separates the conditioned interior environment from the unconditioned exterior. Thus, the energy efficiency of the envelope directly affects the efficiency of the entire building system [1]. Furthermore, if the envelope can capture more daylight for the building, the electrical lighting load will be reduced and further energy savings will be achieved [1]. Compared to a traditional electrical lighting system, daylight is more beneficial for a healthy environment, as well as for human productivity and comfort, as it contains the full spectrum of sunlight [1].

The translucent concrete panel (TCP) system is a multi-functional façade system with an emphasis on light transmission and thermal efficiency without sacrificing load-bearing capacity. In 2001, the first commercially available form of TC was invented by Aron Losonzi [2]. It was composed of glass optical fibers and fine concrete which were combined in such a way that the material was both internally and externally homogeneous. It was manufactured in blocks and panels for decoration. At the Shanghai 
2010 EXPO, Italy took the opportunity to build its pavilion out of TC using about 4000 i.light ${ }^{\circledR}$ blocks,

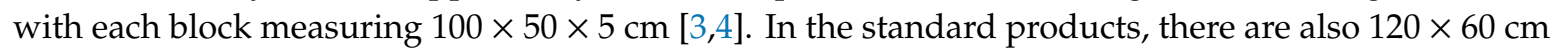
panels with thicknesses of 1.5 or $3 \mathrm{~cm}$ [5]. Another product features plastic fibers arranged in a perfect grid-namely Pixel Panels—which were developed by Bill Price [6]. These panels transmit light from one surface of a wall to the other, but in a pattern whereby the light that shines through the panel resembles tiny stars in a night sky. The University of Detroit-Mercy also developed a process to produce translucent panels made of Portland cement and sand and reinforced them with a small amount of chopped fiber glass [6]. The primary focus of the TC technology has previously been on its esthetic appeal and its application in artistic design; few researchers have investigated its multi-physical properties. He et al. (2011) [7] published a study on smart TC and its light-transmitting, mechanical and self-sensing properties, including the long-term durability of the material. Huang and Mosalam (2015) [8] manufactured TCPs with various densities of optical fibers (OFs), and a series of tests were conducted to understand their multi-physical properties. To investigate the energy consumption savings of TCPs in a building envelope, Ahuja et al. (2015) [9] and Ahuja and Mosalam (2017) [10] performed computational modeling and analysis; the results showed that a TCP façade can cut down energy expenditure by $18 \%$ with a fiber volumetric ratio of $5.6 \%$, which made the fabrication process practical. However, a comprehensive experimental study of TCP has not yet been developed to address the issue of structural performance and energy efficiency.

Compared to a traditional glass curtain wall, a façade with TCPs has higher durability but can be heavier and thicker. In this paper, a group of formworks made of acrylic sheets was fabricated. OF cages were constructed using perforated steel sheets, meaning that the OFs could be easily inserted into the perforations of these sheets and subsequently placed in the formwork. This was followed by the inclusion of a lightweight mortar consisting of sand, cement, silica fume, super-plasticizer, etc. to reduce the self-weight of the TCPs. For comparison, several TCPs with different volumetric ratios (VRs) of OFs were cast in light-weight and normal-weight mortar panels. To understand the multi-physical properties of the TCP, compressive strength, thermal and light transmission, solar heat gain coefficient (G-value), thermal transmittance (U-value) and light transmittance tests were carried out with respective experimental facilities. The experimental results demonstrated that TCPs will be useful for future studies on energy-efficient buildings.

\section{TCP Specimen}

The construction materials consisted of sand, cement, additives, perforated steel sheets, optical fibers and acrylic sheets. Normal-weight and lightweight mortars (NWM, LWM) were cast for the different TCPs (Table 1). The NWM and LWM had different mix proportions because the main objective of the LWM was to reduce the self-weight of panels. Therefore, materials such as shrinkage reducing admixture (SRA) and super plasticizer (SP) had to be added to the LWM. For quality control, standard size cubes $(100 \times 100 \times 100 \mathrm{~mm})$ and cylinders $(200 \times 100 \mathrm{~mm})$ were cast with the TCPs.

Table 1. Mix proportions of mortars (target strength $=50 \mathrm{~N} / \mathrm{mm}^{2}$ ).

\begin{tabular}{ccccccccc}
\hline Type & W/C & $\begin{array}{c}\text { Water } \\
\left(\mathbf{k g} / \mathbf{m}^{3}\right)\end{array}$ & $\begin{array}{c}\text { Cement } \\
\left(\mathbf{k g} / \mathbf{m}^{3}\right)\end{array}$ & $\begin{array}{c}\text { Fly ash } \\
\left(\mathbf{k g} / \mathbf{m}^{3}\right)\end{array}$ & $\begin{array}{c}\text { Silica Fume } \\
\left(\mathbf{k g} / \mathbf{m}^{3}\right)\end{array}$ & $\begin{array}{c}\text { Fine Aggregate } \\
\left(\mathbf{k g} / \mathbf{m}^{3}\right)\end{array}$ & $\begin{array}{c}\text { SRA } \\
\left(\mathbf{k g} / \mathbf{m}^{3}\right)\end{array}$ & $\begin{array}{c}\mathbf{S P} \\
\left(\mathbf{k g} / \mathbf{m}^{3}\right)\end{array}$ \\
\hline NWM & 0.50 & 253.0 & 405.0 & 101.0 & 0.0 & 1391.0 & 0.0 & 0.0 \\
\hline LWM & 0.35 & 258.0 & 742.0 & 0.0 & 65.0 & 335.0 & 20.0 & 4.5 \\
\hline
\end{tabular}

Notes: $\mathrm{W} / \mathrm{C}=$ water cement ratio; in normal-weight mortar (NWM), natural sand was used, while in light-weight mortar $(\mathrm{LWM})$, cenospheres were used as micro-aggregate; $\mathrm{SRA}=$ shrinkage reducing admixture; $\mathrm{SP}=$ super plasticizer.

OFs are commonly used as light conduits. It should be noted that, for a plastic OF, the core can be polystyrene or polymethyl methacrylate, and the cladding is generally silicone or Teflon. On the other hand, for glass OF, both the cladding and the core are made of silica with a small amount of 
dopant-e.g., boron or germanium—to change its refractive index [11]. A glass OF was not employed in this study because it is very easy to break due to bending. According to previous parametric studies [12-16], OFs transmit light without any attenuation along the total length (up to $1.0 \mathrm{~m}$ ) of the fibers. Moreover, considering the actual construction conditions, the bending diameter of the OF should be larger than 12 times the diameter of the OF; i.e., the bending diameter should be no more than $36 \mathrm{~mm}$ for an OF with a diameter of $3 \mathrm{~mm}$. Physical properties of the OF are listed in Table 2. In the present investigation, OFs were used to construct the TCPs.

Table 2. Properties of the optical fibers (OFs) [17].

\begin{tabular}{cc}
\hline Property & Specification \\
\hline Core material & Polymethyl-methacrylate $($ PMMA) resin \\
Cladding material & Fluorinated polymer \\
Core refractive index & 1.49 \\
Refractive index profile & Step-index \\
Numerical aperture & 0.50 \\
Core diameter $(\mu \mathrm{m})$ & $2765-3125$ \\
Cladding diameter $(\mu \mathrm{m})$ & $2820-3180$ \\
Approximate weight $(\mathrm{g} / \mathrm{m})$ & 8.6 \\
Tensile strength $(\mathrm{N})$ & 550.0 \\
\hline
\end{tabular}

\subsection{Volumetric Ratio (VR)}

There is a relationship between this clear spacing and the fiber VR of the TCP (Figure 1), where the spacing is determined by the diameter of the fiber and the VR. In Figure 1, as an example, the maximum aggregate size is limited to $10 \mathrm{~mm}$ for a fiber diameter of $3 \mathrm{~mm}$ with the required $4 \% \mathrm{VR}$. A large number of small-diameter fibers makes the placing of concrete more cumbersome compared to a smaller number of large-diameter fibers for the same VR. Moreover, laying the small-diameter fibers in the formwork requires intensive labor. In the current study, only sand is used in the mortar mix; therefore, the limitations on the aggregate size are automatically satisfied.

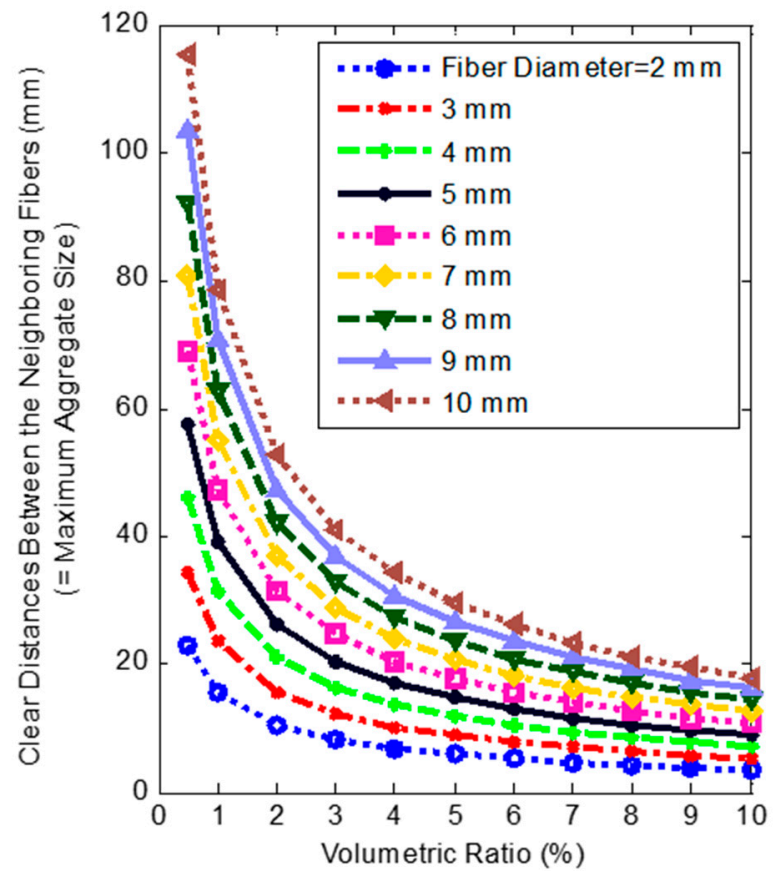

Figure 1. Effect of volumetric ratio and diameter on the required clear spacing between fibers [8]. 
Six TCPs $(300 \times 300 \times 30 \mathrm{~mm})$ were constructed in this study-three with NWM and three with LWM. OFs with a $3 \mathrm{~mm}$ (1/8 inch) diameter were inserted in the panels to transmit daylight through the TCP. Considering the arrangement of the holes in the perforated steel sheets, the VRs of the fibers were $1.5 \%, 3.0 \%$ and $6.0 \%$. To understand the thermal transmission effect of the OFs, two opaque panels with the same dimensions were cast as well, both with NWM and LWM. The visual effects of the completed TCPs are shown in Figure 2. The density of the NWM and LWM panels were 21.4 and $14.1 \mathrm{kN} / \mathrm{m}^{3}$, respectively.

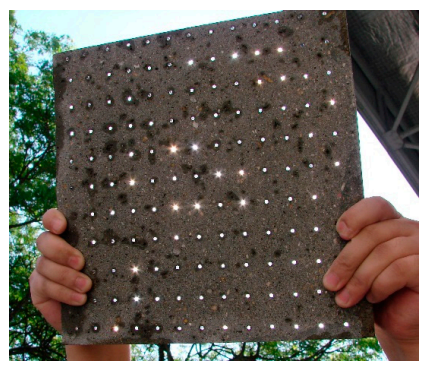

(a)

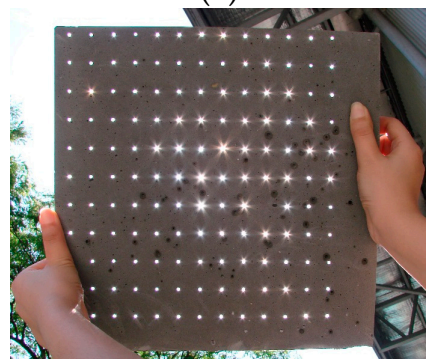

(d)

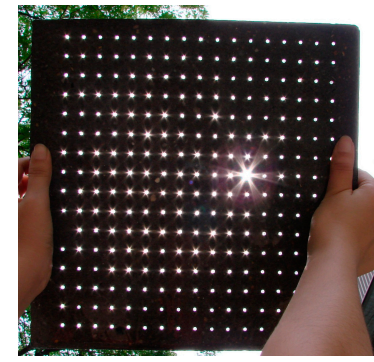

(b)

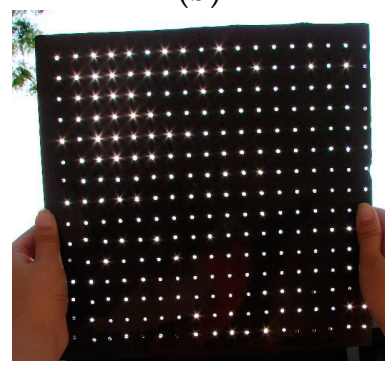

(e)

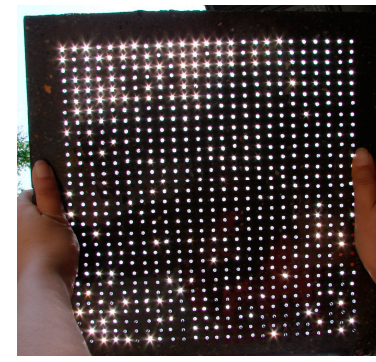

(c)

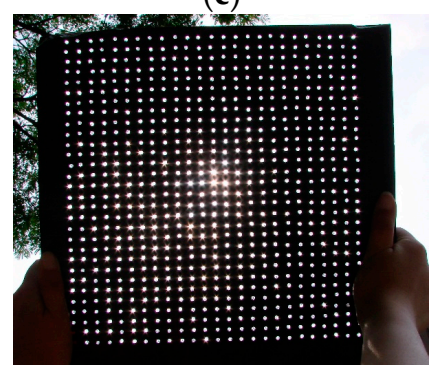

(f)

Figure 2. Completed translucent concrete panels (TCPs) (VR = volumetric ratio): (a) VR of 1.5\% (NWM); (b) VR of $3.0 \%$ (NWM); (c) VR of $6.0 \%$ (NWM); (d) VR of $1.5 \%$ (LWM); (e) VR of $3.0 \%$ (LWM); (f) VR of $6.0 \%$ (LWM).

\subsection{Compressive Strength}

For each type of concrete (NWM, and LWM), six standard cylinders were cast with the TCPs and then placed into a fog room for maintenance. After 28 days, they were taken out for compressive strength testing with a universal testing machine (Figure 3a). The loading rate was $0.10 \mathrm{~mm} / \mathrm{min}$ with displacement control, which complied with the specification of ASTM C617 (2015) [18] and ASTM C39 (2018) [19]. With this method, the post-peak branch of the stress-strain curve could be captured. The stress-strain relationship from the cylinders was observed (Figure 3a). In the test, the typical fracture pattern of the cylinder was columnar vertical cracking through both ends, and no well-formed cones were found in each cylinder (Figure $3 b, c)$. The rupture progress in the NWM cylinder was much slower than that of the LWM. There were slight forewarnings, such as the appearance of the development of cracks in the surface of the cylinder. The stress-strain curves clearly exhibited the damage mode of the two types of cylinders (Figure 4). The NWM cylinders achieved peak stress at 40.0 to $50.0 \mathrm{~N} / \mathrm{mm}^{2}$, then decreased slowly after that. However, the resulting compressive stress of the LWM cylinders dropped suddenly after higher peak values (approximately $60.0 \mathrm{~N} / \mathrm{mm}^{2}$ ), showing that they were more brittle than the NWM cylinders because of the use of SRA and SP. The experimental compressive strengths of the two materials were 39.1 and $58.8 \mathrm{~N} / \mathrm{mm}^{2}$. The compression strength for LWM was about $20 \%$ higher than the observed values for NWM. It should be mentioned that there were no OFs embedded in the cylinders because the primary objective of the tests was to acquire the compressive strength of the NWM and LWM mortars. 


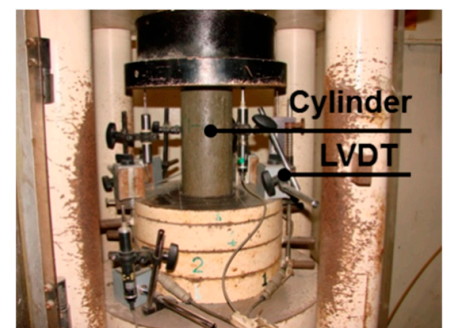

(a)

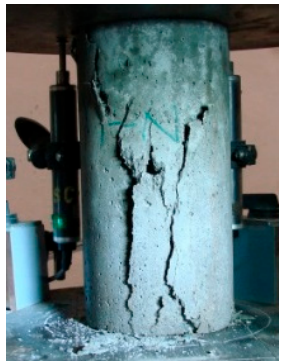

(b)

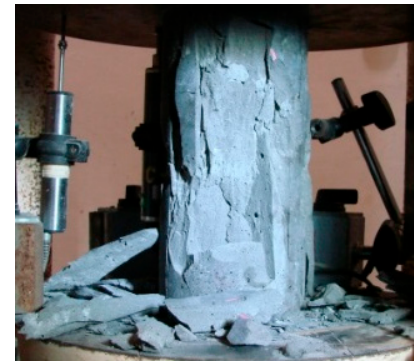

(c)

Figure 3. Compressive strength test of the cylinder: (a) Test setup; (b) columnar cracking (NWM); (c) columnar cracking (LWM).

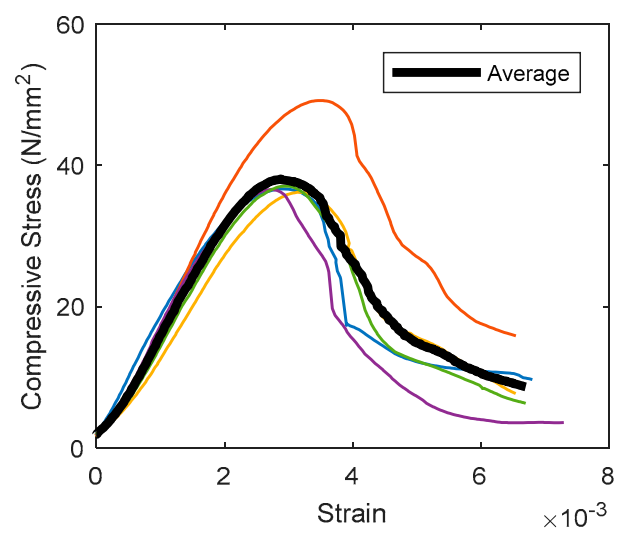

(a)

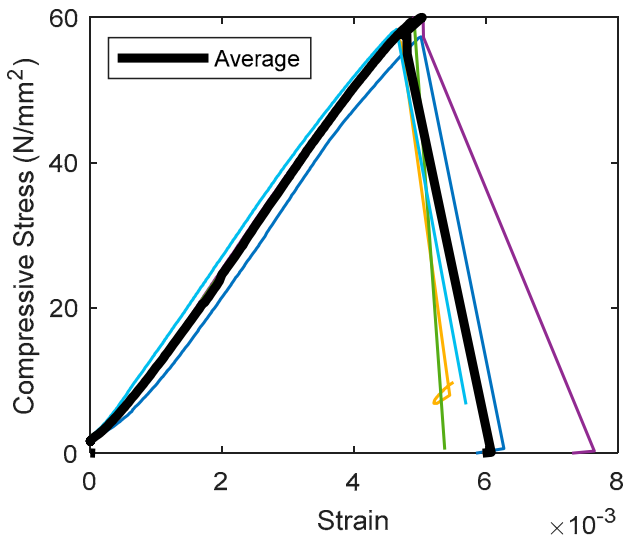

(b)

Figure 4. Stress-strain curves of the cylinders: (a) cylinders with NWM; (b) cylinders with LWM.

\section{Test Methodology}

\subsection{Thermal Property Test}

To evaluate the thermal transmittance ( $U$-value), thermal conductance ( $C$-value), thermal resistance ( $R$-value) and apparent thermal conductivity (K-value) of eight pieces of concrete panels were determined under specific laboratory environmental conditions using the calorimetric hot box (CHB). The thermal transmittance of a specimen, $U$ (in $\mathrm{W} /\left(\mathrm{m}^{2} \mathrm{~K}\right)$ ), is defined as the air-to-air thermal transmission rate:

$$
U=\frac{Q}{\left(T_{a, m}-T_{a, c}\right) A}
$$

where $Q$ is the heat flow rate transmitted through the specimen $(\mathrm{W}), A$ is the specimen area $\left(\mathrm{m}^{2}\right), T_{a, m}$ is the metering side air temperature $\left({ }^{\circ} \mathrm{C}\right)$ and $T_{a, c}$ is the climate side air temperature $\left({ }^{\circ} \mathrm{C}\right)$. The thermal conductance of a specimen, $C\left(\mathrm{~W} /\left(\mathrm{m}^{2} \mathrm{~K}\right)\right)$, is defined as the surface-to-surface thermal transmission rate:

$$
C=\frac{Q}{\left(T_{s, m}-T_{s, c}\right) A}
$$

where $T_{s, m}$ is the metering side specimen surface temperature $\left({ }^{\circ} \mathrm{C}\right)$ and $T_{s, c}$ is the climate side specimen surface temperature $\left({ }^{\circ} \mathrm{C}\right)$. The thermal resistance of a specimen, $R\left(\left(\mathrm{~m}^{2} \mathrm{~K}\right) / \mathrm{W}\right)$, is defined as the surface-to-surface thermal resistance:

$$
R=\frac{1}{C}
$$

Assuming that the specimen is homogeneous, the apparent thermal conductivity of a specimen, $K,(\mathrm{~W} /(\mathrm{m} \cdot \mathrm{K}))$, is defined as

$$
K=C \cdot d
$$


where $d$ is the thickness of the specimen (m).

There is no standardized method available to investigate the thermal properties of the TCP. In the current study, a CHB was used in the tests. Figure 5a shows the schematics of the CHB in the thermal transmittance measurement mode. The box had a size of $1.9 \times 2.1 \mathrm{~m}$ (Figure 5a), and there was a small opening $(0.3 \times 0.3 \mathrm{~m})$ in the middle to mount the testing specimen. The masks (plastic foam insulator sticks), made from the same material as the surrounding panels, were used to fill the spaces between the test specimen and the surround panel opening. Smaller gaps (less than $5.0 \mathrm{~mm}$ ) between the specimen edge and the surround panel opening were filled with cotton wool for thermal insulation. All joints were sealed by boxing tape to ensure airtightness. The outdoor side surface of the specimen was recessed by $25.0 \mathrm{~mm}$ from the outdoor side surface of the surrounding panel. The system consisted of four main components: a metering box surrounded by a guarding box on the indoor side, a climate box on the outdoor side and a surrounding panel holding the test specimen, inserted between the indoor and outdoor side boxes (Figure 5a, Chen et al., 2012) [20]. The global view and the opened CHB are shown in Figure $5 b, c$, respectively.

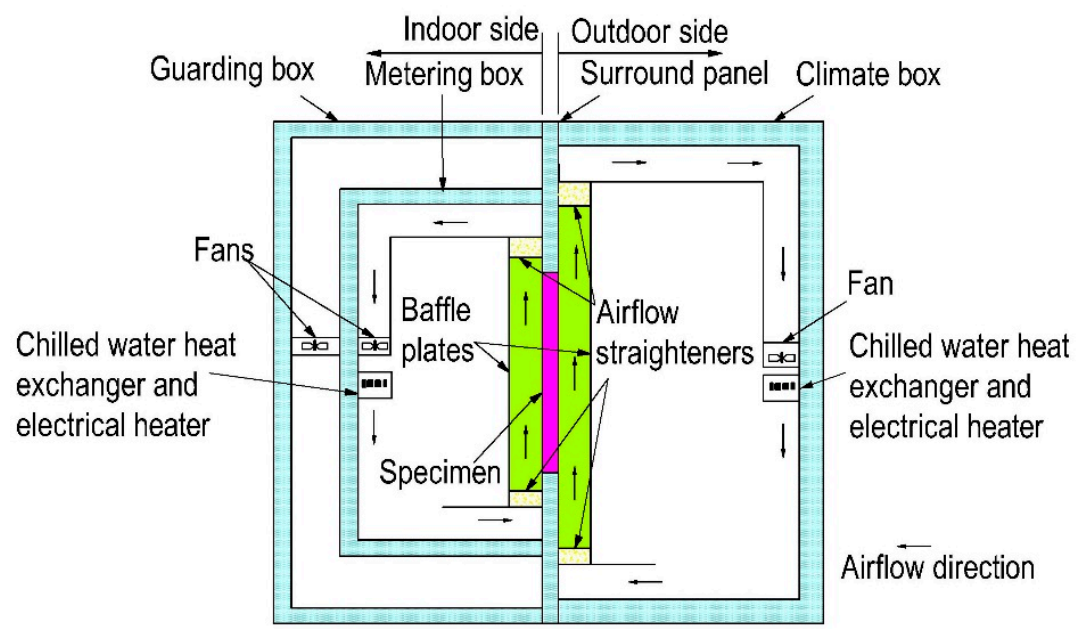

(a)

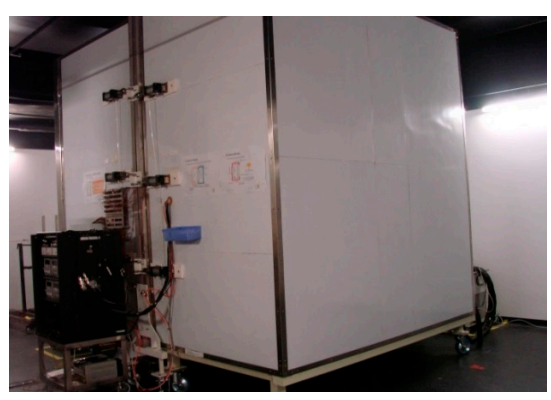

(b)

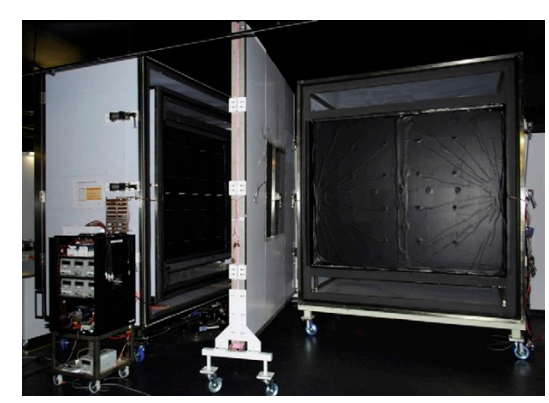

(c)

Figure 5. Calorimetric hot box (CHB) system: (a) schematics of the CHB (Chen et al. 2012a) [20]; (b) closed hot box; (c) opened hot box (Chen et al. 2012a) [20].

The effective metering area of a specimen was uniformly divided into $3 \times 3$ grids, and one thermocouple sensor was attached to the center of each grid for specimen surface temperature monitoring (Figure 6a). In total, 18 thermocouples were used for specimen surface temperature monitoring, with nine on each side. As an example, Figure 6 shows pictures of the installation of the specimen. Figure 6a shows the layout of the thermocouple sensors on the specimen surface. The visual effect from indoor and outdoor sides are shown in Figure $6 \mathrm{~b}, \mathrm{c}$. 


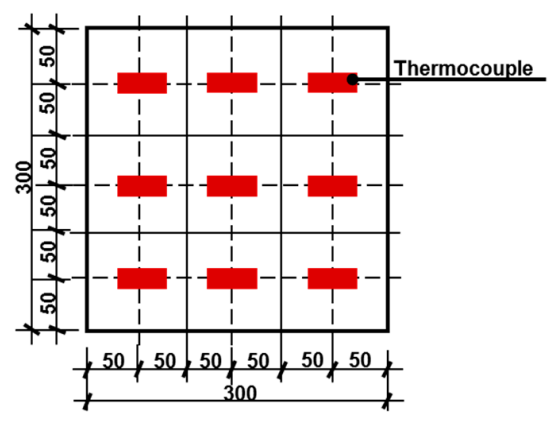

(a)

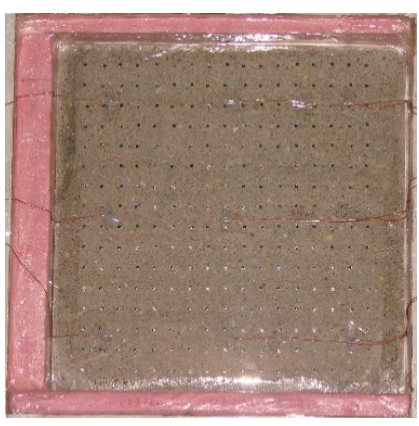

(b)

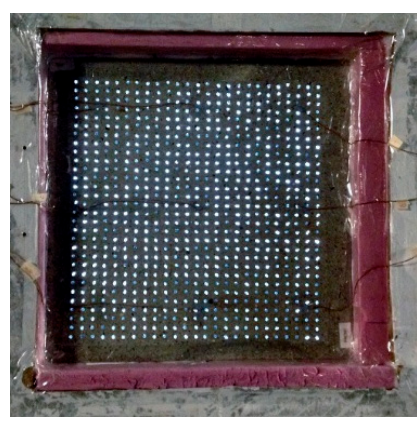

(c)

Figure 6. Installed specimen and thermocouples: (a) layout of the thermocouples; (b) view from outdoor side; (c) view from indoor side.

The thermal transmittance tests were carried out under the environmental conditions given in Table 3. Before conducting the actual test, the box was calibrated for 8 hours to ensure the testing facility worked well. A specimen was mounted vertically in the opening of a well-insulated surround panel made of extruded polystyrene core material (Figure 6b,c). Temperatures in the indoor and the outdoor sides were always maintained at a fixed temperature difference (Table 3). Air flow temperatures/velocities and surface temperatures on both sides were controlled or monitored to maintain the desired environmental conditions. The steady state heat flow through the specimen due to the temperature difference was measured to calculate the thermal transmittance value. The calculation methods defined in ASTM C1363 [21] were used in the calculations of results. One experimental case required about 25 to 30 hours for experimentation.

Table 3. Simulated micro-environment conditions.

\begin{tabular}{cc}
\hline Environmental Properties & Temperature/Air Flow \\
\hline Indoor side air temperature & $40{ }^{\circ} \mathrm{C}$ \\
Outdoor side air temperature & $20^{\circ} \mathrm{C}$ \\
Indoor side airflow velocity and direction & $0.3 \mathrm{~m} / \mathrm{s}$, vertically upwards \\
Outdoor side airflow velocity and direction & $3.5 \mathrm{~m} / \mathrm{s}$, vertically upwards \\
\hline
\end{tabular}

\subsection{Solar Heat Gain Coefficient (SHGC, G-Value) Test}

The solar heat gain coefficient (SHGC) —also named the G-value or solar factor-is the total solar energy transmittance factor through a glazing system separating two environments (generally outdoor and indoor) [22-24]. It is the fraction of external solar radiation that is admitted through a window or façade, both directly transmitted and absorbed and subsequently released inward [25]. A standardized definition of this magnitude in the case of transparent glazing systems is mainly given by ISO 9050 (2003) [26], and EN 410 (2011) [27] for a simplified calculation where the resolution of the non-linear system of equations for the heat balance is avoided. A detailed calculation is provided in ISO 15099 (2003 [28]) and EN 13363-2 (2005) [29], in which conductive-convective and radiative parts of the heat transport problem are coupled through the temperature nodes. The latter standards follow an approach with different conditions by considering either a node of temperature in each glass surface or a sole node for each layer, respectively. The G-value can be used to describe the properties of the façade as a whole, or parts of it (e.g., windows) or of components (e.g., insulating glazing units). Most related studies in the literature have focused on transparent or translucent building glazings, such as glass windows [24,30] or transparent solar thermal collectors [31], with studies on the energy efficiency of TCPs as building envelopes being rare.

In this section, the SHGC was measured with a CHB similar to that used in Figure 5. Some well-developed thermal transmittance experimental methods [32-35] were applied to the two TCPs 
with a VR of $6 \%$. The SHGC of a specimen, G, is defined as the ratio of transmitted solar heat to the incident solar heat, and is calculated as

$$
G=\frac{Q_{S, G}}{I_{S} A_{S}}
$$

where $Q_{\mathrm{S}, \mathrm{G}}$ is the heat flow rate transmitted through the specimen due to solar heat gain $(\mathrm{W}), A_{\mathrm{S}}$ is the projected specimen surface area $\left(\mathrm{m}^{2}\right)$ and $I_{S}$ is the mean incident solar irradiance on the specimen plane $\left(\mathrm{W} / \mathrm{m}^{2}\right)$. When the steady state is attained in the metering box, $Q_{S, G}$ can be determined from the heat balance.

The CHB is a combined thermal transmittance and SHGC measurement system. Figure 7 shows the schematic cross-sectional view of the SHGC measurement mode. The metering box, guarding box and surround panel used in the thermal transmittance measurement mode were used for the indoor environmental simulation, but on the outdoor side, the climate box was replaced with a solar simulator and an external air curtain. Additionally, the indoor side boxes-i.e., the guarding and metering boxes-were mounted on an automated turning system for angular SHGC measurements.

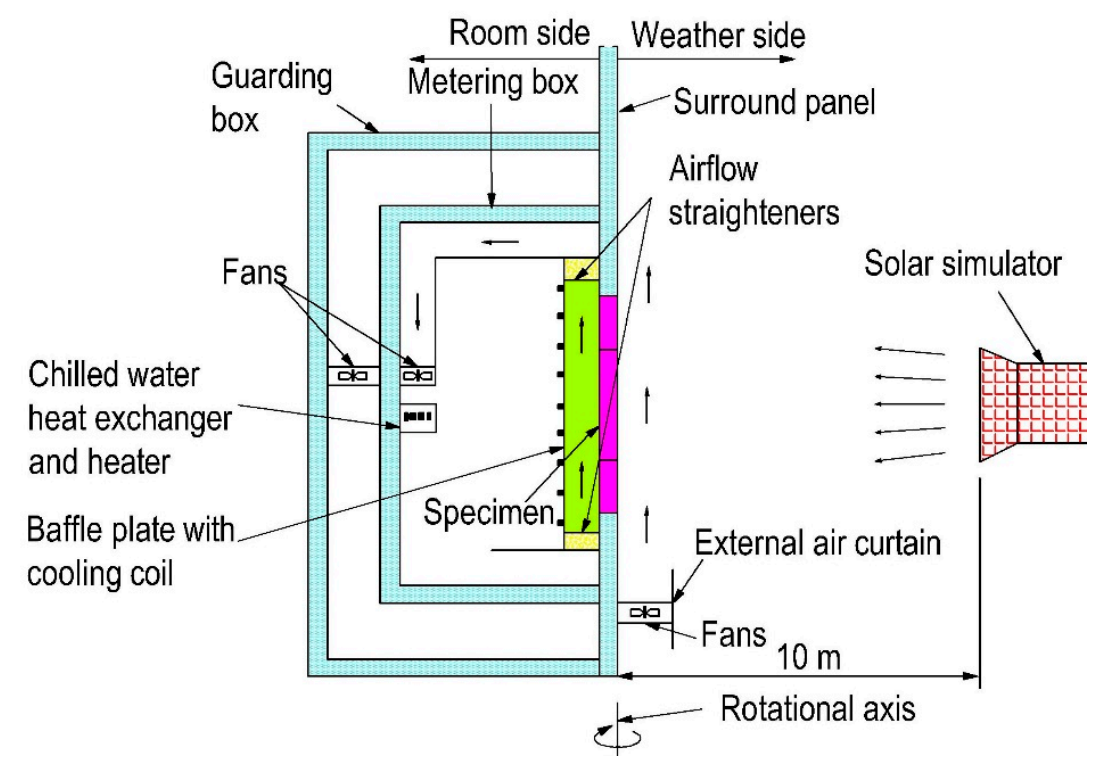

Figure 7. Layout of the test [32].

A lamp was used as the solar simulator (Figure 8). To achieve a small divergence angle and an improvement in uniformity, the lamp system was located $10 \mathrm{~m}$ away from the TCP (Figure 7). Figure 9 shows the normalized solar simulator spectrum in the wavelength range of 0.3 to $1.678 \mu \mathrm{m}$, in comparison with the standard AM1.5 (air mass = 1.5) direct normal irradiance spectra recommended by ISO 9845 (1992) [36], ISO 9050 (2003) [26] and ASTM G-173 (2012) [37]. A spectrometer with a nominal measurement range of 0.3 to $1.7 \mu \mathrm{m}$ was used; in fact, it is believed that the measured range was sufficiently representative because it contained approximately $93.5 \%$ of the total solar energy in the 0.3 to $2.5 \mu \mathrm{m}$ range of the standard AM1.5 spectrum. Therefore, the solar spectrum in the range of 1.678 to $2.5 \mu \mathrm{m}$ was assumed to be identical to the standard AM1.5 spectrum. The achieved mean irradiance was $621.0 \mathrm{~W} / \mathrm{m}^{2}$ with a non-uniformity of $\pm 5.6 \%$ [32]. The solar incident angle was $0^{\circ}$ (i.e., perpendicular to the specimen surface) in the tests.

Two TCPs with the same VR of $6 \%$ but different materials (LWM and NWM) were tested. The gaps between the $\mathrm{CHB}$ and the TCP were filled with cotton wool for thermal insulation, then they were sealed by boxing tape to ensure airtightness (Figure 10a,b). The outdoor side surface was recessed $25 \mathrm{~mm}$ from the surface of the CHB (Figure 10a). A pyranometer was put beside the panel to observe the solar irradiance from the light source (Figure 10a). Figure 10b shows the illumination of the solar emulator to the TCP specimen, and Figure 10c shows the appearance of the TCP from the indoor side. 
During the testing process, real-time data acquisition is conducted to capture the whole solar heat transfer process closely.

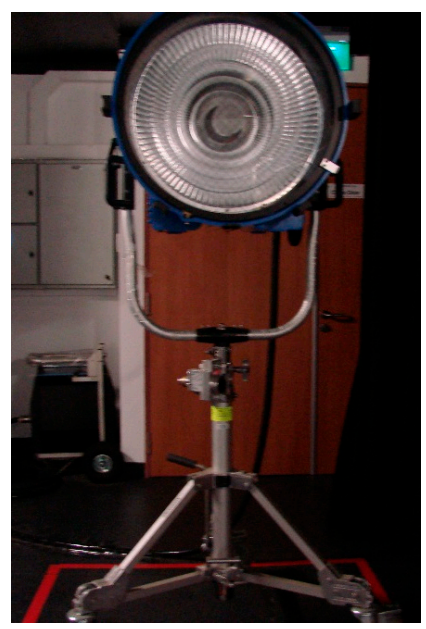

Figure 8. Light source for solar simulator.

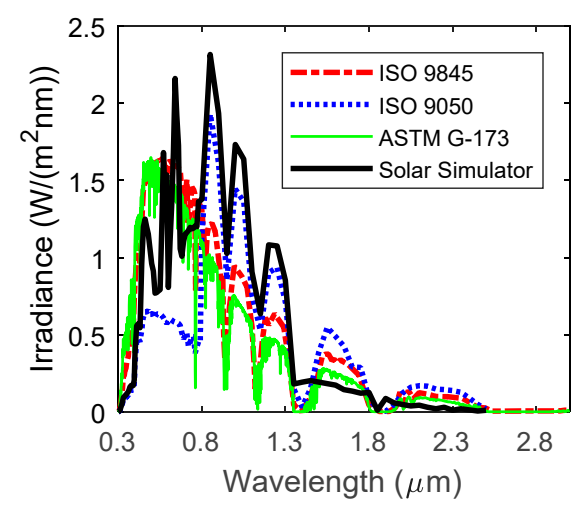

Figure 9. Solar simulator radiation spectrum and reference AM1.5 spectra.

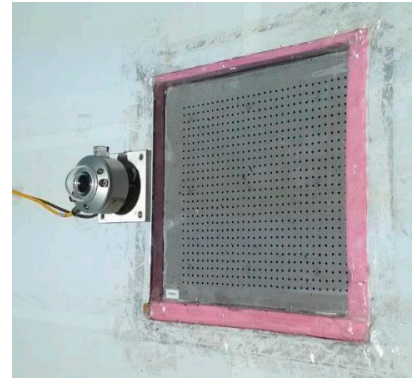

(a)

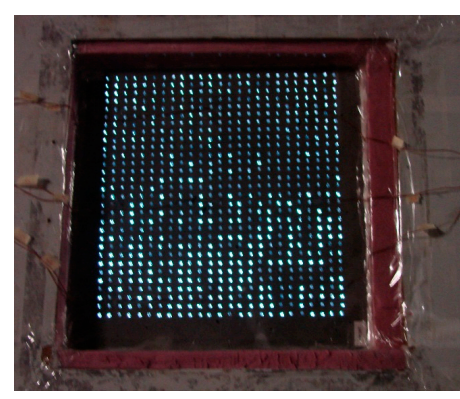

(b)

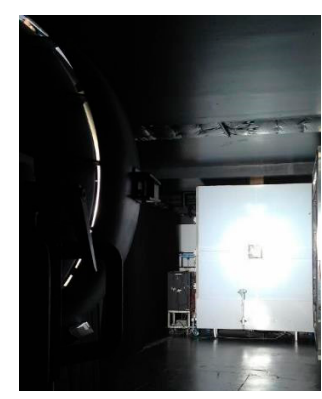

(c)

Figure 10. Test overview (note: indoor and outdoor denote inside and outside the $\mathrm{CHB}$, respectively): (a) view from the indoor side; (b) view from the indoor side; (c) illumination of the TCP.

\subsection{Visible Light Transmittance (VLT) Test}

Generally, an OF consists of two layers of materials, namely the cladding and the core. Figure 11 shows an axial cross-section of a step-index fiber and a light ray that is coupled into the fiber left cross-section [38]. For the light to be coupled into the guided mode in the fiber, total internal reflection has to occur inside the core, requiring $\theta_{i}>\theta_{c}$, as shown in Figure 11, where $\theta_{c}=\arcsin \left(n_{2} / n_{1}\right)$ is the critical angle of the core-cladding interface. With this requirement on $\theta_{i}$, there is a corresponding 
requirement on the incidence angle $\theta_{a}$ at the fiber end surface making use of Snell's law and elementary trigonometry; i.e.,

$$
n_{0} \sin \theta_{a}=n_{1} \sin \theta_{1}=n_{1} \sqrt{\left(1-\sin ^{2} \theta_{i}\right)}
$$

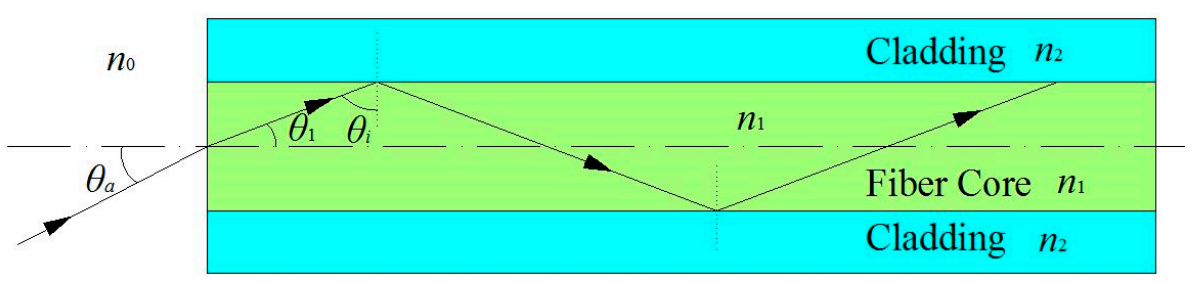

Figure 11. Light transmission in the step index fiber [8].

It should be noted that the fiber core will propagate the incident light rays only when it is incident at an angle greater than the critical angle $\theta_{c}$. If the total internal reflection occurs at the core-cladding interface, we have $\theta_{i}>\theta_{c}$, i.e., $\sin \theta_{i}>\sin \theta_{c}=n_{2} / n_{1}$. This requires the incidence angle $\theta_{a}$ to satisfy the following condition:

$$
n_{0} \sin \theta_{a}<n_{1} \sqrt{\left(1-\sin ^{2} \theta_{c}\right)}=n_{1} \sqrt{1-\left(n_{2} / n_{1}\right)^{2}}=\sqrt{n_{1}^{2}-n_{2}^{2}}
$$

The light entering an OF within a cone defined by the half-acceptance angle, $\theta_{a}$, is converted into guided modes and can propagate along the fiber. The imaginary light cone with twice the acceptance angle as the vertex angle is known as the acceptance cone. Outside this cone, the light coupled into a fiber will radiate into the cladding. Similarly, the light exiting a fiber has a divergence angle defined by the numerical aperture. This property is critical for the fiber to capture daylight. For the OFs in the TCPs, using Equations (6) and (7), the calculated half-acceptance angle is $33.0^{\circ}$.

The objective of this test was to measure the VLT of six TCPs at a normal incident angle and two TCPs at five oblique incident angles $\left(20^{\circ}, 30^{\circ}, 40^{\circ}, 50^{\circ}\right.$, and $\left.60^{\circ}\right)$ by moving the light source held by the arm fixed to its bottom (Figure 12). An integrating sphere of $1.25 \mathrm{~m}$ in size, designed and constructed according to CIE 38 (Commission Internationale de 1'Eclairage, 1990) and CIE $130(1998)$ [39,40], was used to measure the directional-to-hemispherical total VLT. The light source spectrum was close to the CIE standard illuminant D65. The illuminance level in the integrating sphere was measured by a photo-detector. Its sensitivity was close to the CIE photopic luminosity function (CIE 1990). The measurement was carried out with the sample port open and subsequently was covered by the test specimen. The ratio of the two photo-detector readings was the specimen's VLT (NFRC, 2014) [41]. The same procedures were repeated five times for each TCP at five different randomly selected positions on the surface.

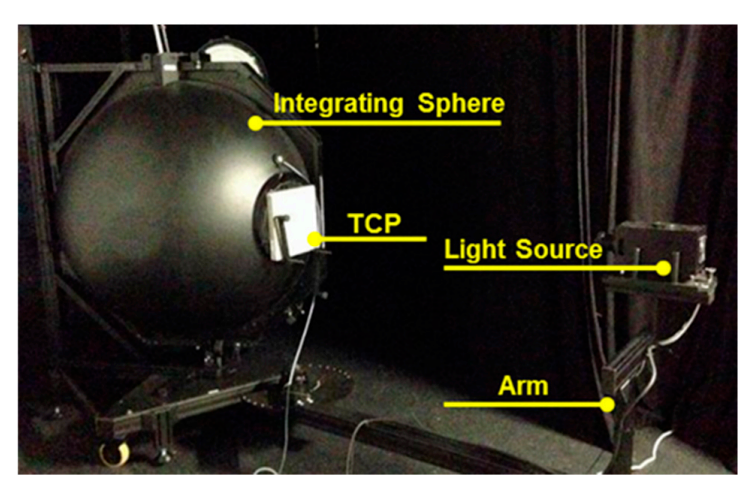

Figure 12. Layout of the test. 


\section{Test Result}

\subsection{Thermal Properties}

The outside surface temperature variation process of each specimen (Figure 13) was observed by the six thermocouples shown in Figure 6a. From Figure 13, it can be seen that the outside surface temperature achieved a stable state after 15 hours. In fact, to ensure the thermal transfer process was fully completed, 48 hours was taken before the termination of the test. Experimental thermal properties such as the U-value, C-value, R-value and K-value of the specimens are shown in Figure 14. U-values of the LWM TCP were larger than that of the NWM (Figure 14a). The existence of the OFs increased the magnitude of the U-value in the two types of the TCPs because the U-value of the OF was larger than that of the plain panel. Similar observations could be found for the C-value (Figure 14a). However, in Figure 14c, the existence of the OFs had an inverse effect on the R-value in the two types of the TCPs; i.e., the peak C-value (Figure 14b) appeared in the NWM TCP with the highest VR, while it occurred in the plain LWM panel without OFs. To compare the experimental thermal properties of the façade panel with common materials-e.g., a glass sheet, granite stone and brick-their corresponding K-values are plotted in Figure 14d (BCA 2008) [22]. It can be easily seen that the K-values of the LWM TCP were smaller than that of the common façade, which proved its excellent energy efficient performance. This potentiality of the replacement of the traditional glass curtain wall system was predictable for the locations in which the lighting requirement was not particularly high. To ensure efficient thermal transmission, the initial outside temperatures for the NWM TCPs with VRs of $0 \%$ and $1.5 \%$ were slightly higher than those of other TCPs.

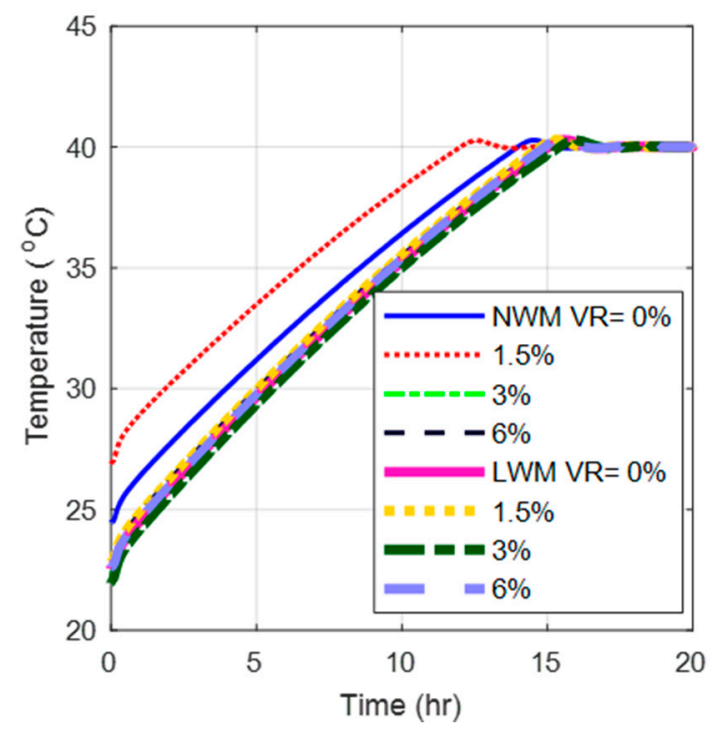

Figure 13. Outside surface temperature variation with time for each specimen.

\subsection{SHGCS}

In the tests, the solar irradiance was about $510.0 \mathrm{~W} / \mathrm{m}^{2}$, the air temperature in the CHB was $24{ }^{\circ} \mathrm{C}$ and the temperature was $23-32{ }^{\circ} \mathrm{C}$ outside of the $\mathrm{CHB}$. The airflow velocity was $0.26 \mathrm{~m} / \mathrm{s}$ in the $\mathrm{CHB}$, and $2.5 \mathrm{~m} / \mathrm{s}$ outside of the $\mathrm{CHB}$; both moved vertically upward. The experimental SHGC values of the two TCPs are listed in Table 4; these were 0.198 and 0.242 for the LWM and NWM TCPs, respectively. They are shown in Figure 15 with the experimental results found by other researchers [42-47]; it can be seen that the SHGC values of the TCPs were lower than those of the laminated glass (McCormick et al., 2017) [42], argon gas-laminated glass (Koo et al., 2018) [43], semi-transparent building integrated photovoltaic panels (BIPV, Mazzali et al., 2015; Ng 
and Mithraratne, 2014; Olivieri et al., 2015) [44-46], etc. in window glazing (Figure 15). Therefore, the potential application of the TCP façade was shown to be the best.

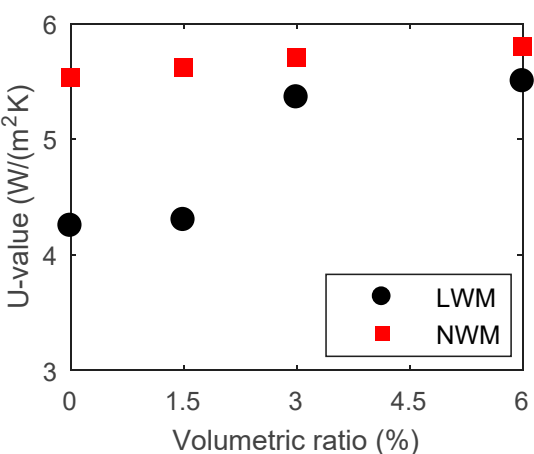

(a)

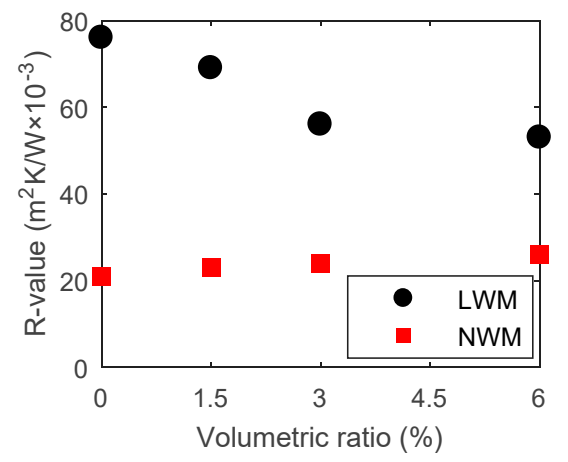

(c)

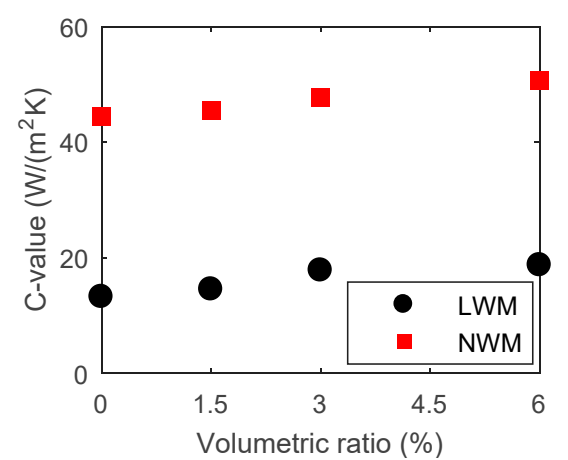

(b)

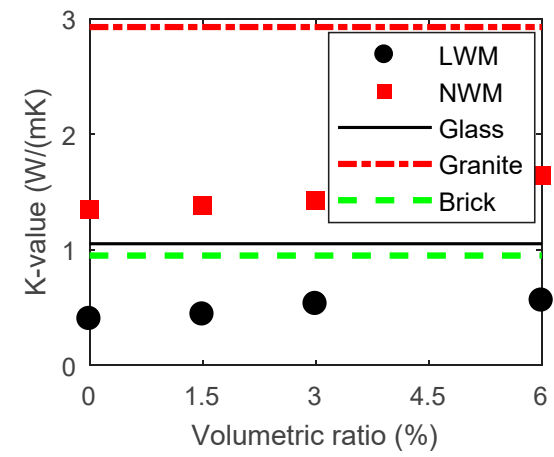

(d)

Figure 14. Thermal properties: (a) U-value; (b) C-value; (c) R-value; (d) K-value.

Table 4. Experimental data. SHGC = solar heat gain coefficient.

\begin{tabular}{ccc}
\hline Item & LWM & NWM \\
\hline Average metering air temperature $\left({ }^{\circ} \mathrm{C}\right)$ & 24.0 & 24.0 \\
Average external air curtain temperature $\left({ }^{\circ} \mathrm{C}\right)$ & 26.9 & 27.0 \\
Metering airflow velocity $(\mathrm{m} / \mathrm{s})$ & 0.26 & 0.26 \\
External air curtain velocity $(\mathrm{m} / \mathrm{s})$ & 2.5 & 2.5 \\
Specimen heat flow rate $(\mathrm{W})$ & 9.0 & 11.1 \\
Solar irradiance $\left(\mathrm{W} / \mathrm{m}^{2}\right)$ & 510.0 & 508.0 \\
SHGC & $0.198 \pm 0.033$ & $\mathbf{0 . 2 4 2} \pm \mathbf{0 . 0 3 4}$ \\
\hline
\end{tabular}

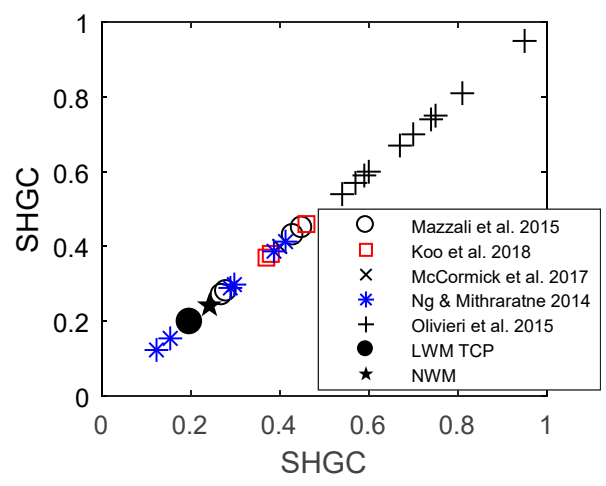

Figure 15. Experimental SHGCs. 


\subsection{VLT}

The VLT of the TCPs was observed under normal incident visible lighting illumination (Table 5). To obtain a reliable average value, each TCP was tested four times. The results showed that (1) the VLT increased with the density of the OFs in the TCP, and (2) the VLT values of the TCPs with $1.5 \%$ and $3.0 \%$ OFs were slightly smaller than their OF densities $(1.1 \%, 2.3 \%)$, while they were larger than the OF densities in the TCP with $6.0 \%$ density $(6.9 \%)$-this was due to the light rays falling into the light acceptance cone of the OFs that were actually transmitted - and (3) the material types (LWM or NWM) had no effect to the TCPs' light transmittance performance, which was determined only by the amount of the OFs.

Table 5. Visible light transmittance (VLT) of the TCPs (\%).

\begin{tabular}{ccccccc}
\hline TCP Type & \multicolumn{3}{c}{ NWM } & & \multicolumn{3}{c}{ LWM } & \\
\hline VR & $\mathbf{1 . 5}$ & $\mathbf{3 . 0}$ & $\mathbf{6 . 0}$ & 1.5 & 3.0 & 6.0 \\
\hline Test 1 & 1.1 & 2.3 & 6.9 & 1.1 & 2.1 & 6.9 \\
2 & 1.2 & 2.3 & 7.0 & 1.0 & 2.1 & 6.9 \\
3 & 1.0 & 2.3 & 7.0 & 1.1 & 1.9 & 6.9 \\
4 & 1.1 & 2.3 & 6.9 & 1.0 & 2.0 & 6.9 \\
5 & 1.1 & 2.3 & 6.9 & 1.1 & 1.9 & 6.9 \\
Average & 1.1 & 2.3 & 6.9 & 1.1 & 2.0 & 6.9 \\
\hline
\end{tabular}

Under the variable oblique light incident angles, the VLT values of two TCPs (LWM and NWM) with the same VR (OF density $=6.0 \%$ ) were tested (Figure 16). The experimental results showed that (1) for the two specimens, the VLT value was reduced with increasing light incidence angles, and (2) under a $20^{\circ}$ light illuminance angle, the actual transmittance was $6.8 \%$, which was identical to the effect of the normal light ( $6.9 \%$ in Table 5). This shows that, besides the direct normal light rays, the lights rays falling into the light acceptance cone (Figure 11) of the OFs were transmitted. However, once the incidence angle increased to $30^{\circ}$, the transmittance dropped to $5.4 \%$, but the difference to the actual OF density was $16.7 \%$. The LVT decreased faster when the incidence angle was larger than $35^{\circ}$; thus, the light acceptance angle was defined as $35^{\circ}$, which was close to the computational result elaborated in Section 3.3. The two TCPs with different materials (LWM and NWM) showed similar behaviors in the test.

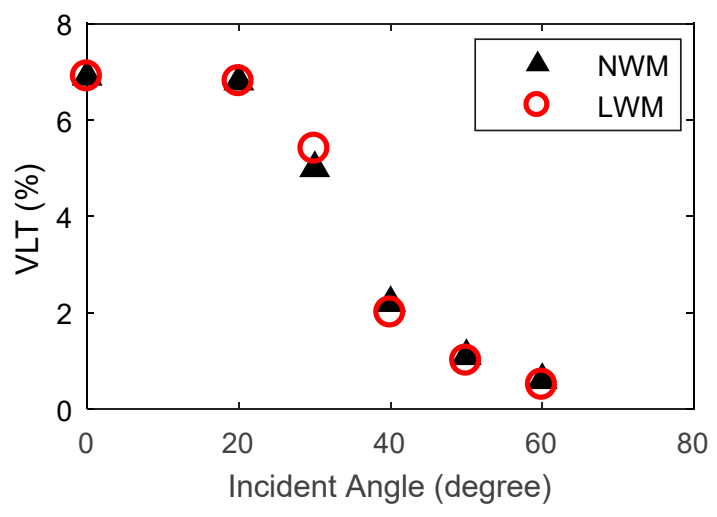

Figure 16. Experimental VLT.

\section{Conclusions and Future Research}

\subsection{Conclusions}

TCPs represent a novel sustainable material for building envelopes because of their energy efficiency. TCPs with various VRs of OFs were constructed with LWM and NWM materials. 
To understand their mechanical, thermal and light transmittance properties, tests were carried out. Some concluding remarks are given below:

(1) The mechanical properties of the NWM and LWM mortars determine the load-bearing capacity of the two materials. As a result of the proper mixing ratio of the materials, the compressive strength of the LWM was higher than that of the NWM, while the LWM was more brittle than the NWM.

(2) The U-values of the plain panel were 4.25 and $5.45 \mathrm{~W} /\left(\mathrm{m}^{2} \mathrm{~K}\right)$ for TCPs with $\mathrm{LWM}$ and NWM, respectively. The existence of the OFs improved the thermal insulation property. The K-values of the LWM TCP were smaller than that of the common façade, which proved its excellent energy efficient performance. This potentiality of replacement of the traditional glass curtain wall system was predictable in the locations where the lighting requirement was not particularly high (Huang, 2020) [48].

(3) The SHGCs (G-values) of the two tested TCP types-LWM and NWM-were 0.198 and 0.242 , respectively.

(4) The VLT tests showed that the light transmitted by the TCP was proportional to the density of the OFs in a matrix of concrete. The experimental light acceptance angle of the OF was measured to be $35^{\circ} \mathrm{C}$, which was close to the computational value shown by Equations (6) and (7).

\subsection{Future Research}

In future research, further studies should be conducted based on the findings of the tests listed above.

(1) The effect of the optical fibers on the mechanical strength of the TCP will be determined in future study.

(2) The integration of OFs into TCPs with compound parabolic concentrators [48,49], including parametric analysis by building numerical models using commercial software, should be explored.

(3) The multi-physical analysis of the TCPs should be conducted considering thermal, light transmission and mechanical actions. Furthermore, numerical analysis and physical testing approaches should be developed to comprehensively evaluate the overall performance of the building façade.

Author Contributions: Conceptualization, B.H.; methodology, B.H.; software, B.H.; writing-original draft preparation, B.H.; writing-review and editing, W.L.; project administration, W.L.; funding acquisition, W.L. All authors have read and agreed to the published version of the manuscript.

Funding: This work was partially supported by China National Science Foundation under award numbers 51608381, 51078290, and 51578405, the International Joint Research Laboratory of Earthquake (ILEE) through grant number ILEE-IJRP-P2-P3-2017, and China Ministration of Science and Technology Major Project through grant number 2016YFE0105600.

Acknowledgments: The Solar Energy Research Institute of Singapore (SERIS) provided facilities for the tests conducted in this report, and Fangzhi Chen gave technical help in the SERIS lab. Minhong Zhang of the National University of Singapore provided facilities for the construction and mechanical testing of the TCPs. The presented research was partially funded by the Republic of Singapore's National Research Foundation through a grant to the Berkeley Education Alliance for Research in Singapore (BEARS) for the Singapore-Berkeley Building Efficiency and Sustainability in the Tropics (SinBerBEST) Program. BEARS has been established by the University of California, Berkeley as a center for intellectual excellence in research and education in Singapore.

Conflicts of Interest: The authors declare no conflict of interest.

\section{References}

1. Edwards, L.; Torcellini, P. A Literature Review of the Effects of Natural Light on Building Occupants; NREL/TP-550-30769; National Renewable Energy Laboratory: Golden, CO, USA, 2002.

2. Litracon. Available online: http://www.litracon.hu/ (accessed on 11 July 2012). 
3. Bates, D. Mortar This than Meets the Eye: The 'Transparent' Cement that Lets Daylight Flood into a Room. 2010. Available online: http://www.dailymail.co.uk/sciencetech/article-1344383/Transparent-light-cementlets-light-flood-room.html (accessed on 6 September 2020).

4. Hipstomp. Transparent Concrete and Cement at World Expo. 2010. Available online: http://www.core77.com/ blog/materials/transparent_concrete_and_cement_at_world_expo_16562.asp (accessed on 6 September 2020).

5. Lucem. Available online: http://www.lucem.de/fileadmin/templates/Downloads/Planungsordner/ LUCEMplanningfolderenglisch_email.pdf (accessed on 6 September 2020).

6. Klemenc, S.E. Wave of the Future: 21st Century Concrete on Display. 2011. Available online: http: //www.concretedecor.net/Articles/CD404/CD404_transparent_concrete.cfm (accessed on 6 September 2020).

7. He, J.; Zhou, Z.; Ou, J.Study on smart transparent concrete product and its performances. In Proceedings of the 6th International Workshop on Advanced Smart Materials and Smart Structures Technology (ANCRiSST2011), Dalian, China, 25 July 2011; p. 107.

8. Huang, B.; Mosalam, K. Construction and Testing of the Energy Efficient Translucent Concrete Panels; Structural Engineering Mechanics and Materials (SEMM) Report No. UCB/SEMM-[2015/04]; University of California: Berkeley, CA, USA, 2015.

9. Ahuja, A.; Mosalam, K.M.; Zohdi, T.I. Computational modeling of translucent concrete panels. J. Arch. Eng. 2015, 21, 4014008. [CrossRef]

10. Ahuja, A.; Mosalam, K.M. Evaluating energy consumption saving from translucent concrete building envelope. Energy Build. 2017, 153, 448-460. [CrossRef]

11. Lacy, E. Fiber Optics; Prentice-Hall: Englewood Cliffs, NJ, USA, 1982.

12. Matsui, T.; Nakajima, K.; Toge, K.; Kurashima, T.; Tsubokawa, M. Fiber identification technique based on mechanically-induced long-period grating for bending-loss insensitive fibers. J. Light. Technol. 2010, 28, 3556-3561. [CrossRef]

13. Gupta, S.C. Textbook on Optical Fiber Communication and Its Applications; Prentice Hall of India: Delhi, India, 2005.

14. Wang, Q.; Farrell, G.; Freir, T. Theoretical and experimental investigations of macro-bend losses for standard single mode fibers. Opt. Express 2005, 13, 4476-4484. [CrossRef] [PubMed]

15. Tangnon, G.L.; Hsu, H.P.; Jones, V.; Pikulshi, J. Bend loss measurements for small mode field diameter fibers. Electron. Lett. 1989, 25, 142-143. [CrossRef]

16. Renner, H. Bending losses of coated single-mode fibers: A simple approach. J. Light. Technol. 1992, 10, 544-551. [CrossRef]

17. Industrial Fiber Optics. Available online: http://i-fiberoptics.com/fiber-detail.php?id=114 (accessed on 24 April 2018).

18. ASTM International. ASTM C39/C39M-19: Standard Test Method for Compressive Strength of Cylindrical Concrete Specimens; ASTM International: West Conshohocken, PA, USA, 2018.

19. ASTM International. C617/C617M-15: Standard Practice for Capping Cylindrical Concrete Specimens; ASTM International: West Conshohocken, PA, USA, 2015.

20. Chen, F.; Wittkopf, S.K. Summer condition thermal transmittance measurement of fenestration systems using calorimetric hot box. Energy Build. 2012, 53, 47-56. [CrossRef]

21. ASTM International. ASTM C1363-11: Standard Test Method for Thermal Performance of Building Materials and Envelope Assembly by Means of a Hot Box Apparatus; ASTM International: West Conshohocken, PA, USA, 2011.

22. Building and Construction Authority (BCA). Code on Envelope Thermal Performance for Buildings; Building and Construction Authority: Singapore, 2008.

23. Baenas, T.; Machado, M. On the analytical calculation of the solar heat gain coefficient of a BIPV module. Energy Build. 2017, 151, 146-156. [CrossRef]

24. Carlos, J.S.; Corvacho, H. Evaluation of the performance indices of a ventilated double window through experimental and analytical procedures: SHGC-values. Energy Build. 2015, 86, 886-897. [CrossRef]

25. Marinoski, D.L.; Güths, S.; Pereira, F.O.R.; Lamberts, R. Improvement of a measurement system for solar heat gain through fenestrations. Energy Build. 2007, 39, 478-487. [CrossRef]

26. ISO 9050 (International Standard), Determination of Light Transmittance, Solar Direct Transmittance, Total Solar Energy Transmittance, Ultraviolet Transmittance and Related Glazing Factors; ISO: Geneva, Switzerland, 2003.

27. EN 410 (European Standard), Glass in Buildings, Determination of Luminous and Solar Characteristics of Glazing; British Standards Institution: London, UK, 2011. 
28. ISO 15099 (International Standard), Thermal Performance of Windows, Doors and Shading Devices Detailed Calculations; ISO: Geneva, Switzerland, 2003.

29. EN 13363-2 (European Standard), Solar Protection Devices Combined with Glazing-Calculation of Total Solar Energy Transmittance and Light Transmittance_Part 2: Detailed Calculation Method; British Standards Institution: London, UK, 2005.

30. Carlos, J.S.; Corvacho, H.; Silva, P.D.; Castro-Gomes, J.P. Modelling and simulation of a double ventilated window. Appl. Therm. Eng. 2011, 31, 93-102. [CrossRef]

31. Maurer, C.; Kuhn, T.E. Variable g value of transparent façade collectors. Energy Build. 2012, 51, 177-184. [CrossRef]

32. Chen, F.; Wittkopf, S.K.; Ng, P.K.; Du, H. Solar heat gain coefficient measurement of semi-transparent photovoltaic modules with indoor calorimetric hot box and solar simulator. Energy Build. 2012, 53, 74-84. [CrossRef]

33. ASTM International. ASTM C1199-09: Standard Test Method for Measuring the Steady-State Thermal Transmittance of Fenestration Systems Using Hot Box Methods; ASTM International: West Conshohocken, PA, USA, 2009.

34. National Fenestration Rating Council. NFRC 200-2010, Procedure for Determining Fenestration Product Solar Heat Gain Coefficient and Visible Transmittance at Normal Incidence; National Fenestration Rating Council: Greenbelt, MD, USA, 2010.

35. National Fenestration Rating Council. NFRC 300-2010, Test Method for Determining the Solar Optical Properties of Glazing Materials and Systems; National Fenestration Rating Council: Greenbelt, MD, USA, 2010.

36. Rund, R.C. International Organization for Standardization (ISO). J. AOAC Int. 1992, 75, 196-199. [CrossRef]

37. ASTM International. ASTM G173-03: Standard Tables for Reference Solar Spectral Irradiances: Direct Normal and Hemispherical on $37^{\circ}$ Tilted Surface; ASTM International: West Conshohocken, PA, USA, 2012.

38. Hui, R.; O'Sullivan, M. Fiber Optic Measurement Techniques; Elsevier Academic Press: Burlington, VT, USA, 2009.

39. International Commission on Illumination (CIE). Radiometric and Photometric Characteristics of Materials and Their Measurement, CIE 38 (TC-2.3); CIE Central Bureau: Vienna, Austria, 1990.

40. International Commission on Illumination (CIE). Practical Methods for the Measurement of Reflectance and Transmittance, CIE 130; CIE Central Bureau: Vienna, Austria, 1998.

41. National Fenestration Rating Council, Inc. NFRC 200-2014: Procedure for Determining Fenestration Product Solar Heat Gain Coefficient and Visible Transmittance at Normal Incidence; National Fenestration Rating Council: Greenbelt, MD, USA, 2014.

42. McCormick, E.; Jakubiec, J.A.; Budig, M. Analysis of architectural façade elements in tropical climates for daylight, Thermal Comfort and Passive Climatization. In Proceedings of the 15th IBPSA Conference, San Francisco, CA, USA, 7-9 August 2017; pp. 2540-2548.

43. Koo, B.; Lee, K.; An, Y.-S.; Lee, K.D. Solar heat gain reduction of ventilated double skin windows without a shading device. Sustainability 2017, 10, 64. [CrossRef]

44. Mazzali, U.; Ruggeri, P.; Zinzi, M.; Peron, F.; Romagnoni, P.; Dáneo, A. Set-up and calibration by experimental data of a numerical model for the estimation of solar factor and UG-value of building integrated photovoltaic systems. Energy Procedia 2015, 78, 2202-2207. [CrossRef]

45. Ng, P.K.; Mithraratne, N. Lifetime performance of semi-transparent building-integrated photovoltaic (BIPV) glazing systems in the tropics. Renew. Sustain. Energy Rev. 2014, 31, 736-745. [CrossRef]

46. Olivieri, L.; Frontini, F.; Polo-López, C.; Pahud, D.; Caamano-Martin, E. G-value indoor characterization of semi-transparent photovoltaic elements for building integration: New equipment and methodology. Energy Build. 2015, 101, 84-94. [CrossRef]

47. Kuhn, T.E. Calorimetric determination of the solar heat gain coefficient $\mathrm{g}$ with steady-state laboratory measurements. Energy Build. 2014, 84, 388-402. [CrossRef]

48. Huang, B. Light transmission performance of translucent concrete building envelope. Cogent Eng. 2020, 7, 1756145. [CrossRef]

49. Winston, R.; Miñano, J.C.; Benitez, P. Nonimaging Optics, 2nd ed.; Elsevier Academic Press: London, UK, 2005.

(C) 2020 by the authors. Licensee MDPI, Basel, Switzerland. This article is an open access article distributed under the terms and conditions of the Creative Commons Attribution (CC BY) license (http://creativecommons.org/licenses/by/4.0/). 